\title{
Professor H. M. Srivastava: man and mathematician
}

İsmail Naci Cangül ${ }^{*}$

\section{"Correspondence:}

cangul@uludag.edu.tr

Dean of the Faculty of Arts and

Science, Uludağ University, Görükle

Campus, Bursa, 16059, Turkey

\begin{abstract}
Biography of Professor Hari M. Srivastava.

This article is being published in each of the four Special Issues of the SpringerOpen journals, Advances in Difference Equations, Boundary Value Problems, Fixed Point Theory and Applications and Journal of Inequalities and Applications, which are entitled 'Proceedings of the International Congress in Honour of Professor Hari M. Srivastava'.
\end{abstract}

\section{A brief biographical sketch}

Professor Hari Mohan Srivastava was born on July 5, 1940 at Karon in Ballia district of the province of Uttar Pradesh in India. His father, Mr. Harihar Prasad (1900-1985), was a lawyer practicing in the civil and district courts in Ballia. His mother, Mrs. Bela Devi (1910-1989), was remarkably well versed in the Vedic and Hindu religious scriptures, which greatly influenced his childhood and later life spiritually as well as culturally. His father, on the other hand, significantly strengthened his pre-university education, especially in the subjects of English and Mathematics.

Having had hardly any formal education at the primary school level, in 1946 Professor Srivastava was admitted into grade 3 of the government higher secondary school in Ballia at the age of six after his successful performance in the mandatory written and oral entrance examinations. It is at this school where he was awarded a double promotion from grade 4 to grade 6 , without having to go through grade 5 . This did indeed accelerate his completion of high school (grade 10) in 1953. During the next two years (1953-1955), he studied at B. N. V. College at Rath in Hamirpur district of the province of Uttar Pradesh, where he completed his I. Sc. in 1955, breaking all the existing academic and scholarly records of that College as well as in other colleges in the region.

Professor Srivastava received his university education at the University of Allahabad where he completed his B. Sc. in 1957 and M. Sc. in 1959. Besides being a throughout high first class (right from high school (1953) to M. Sc. (1959)) and meritorious product of the University of Allahabad, and having won a number of merit prizes and scholarships, he was awarded the Allahabad Jubilee Medal in the year 1959. During the period of his fouryear stay at the University of Allahabad (1955-1959), Professor Srivastava also published two first-prize-winning short stories in English, which were subsequently translated and published in other Indian languages (especially in Hindi).

Professor Srivastava began his university-level teaching career in 1959, at the age of 19. He taught at D. M. Government College in Imphal (now Manipur University) during the

\section{Springer}

(c) 2013 Cangül; licensee Springer. This is an Open Access article distributed under the terms of the Creative Commons Attribution License (http://creativecommons.org/licenses/by/2.0), which permits unrestricted use, distribution, and reproduction in any medium, provided the original work is properly cited. 
academic year 1959-1960 and at the University of Roorkee (now the Indian Institute of Technology at Roorkee) during the academic years 1960-1963. He then moved to Jodhpur University (now Jai Narain Vyas University) where he earned his Ph. D. degree in 1965 while he was a full-time member of the teaching faculty at Jodhpur University (since 1963).

Currently, Professor Srivastava holds the position of a professor emeritus in the Department of Mathematics and Statistics at the University of Victoria in Canada. He joined the faculty there in 1969 (first as an associate professor (1969-1974) and then as a full professor (1974-2006)). Professor Srivastava has held numerous visiting positions including (for example) those at West Virginia University in the USA (1967-1969), Université Laval in Canada (1975), and the University of Glasgow in the UK (1975-1976), and, indeed, also at many other universities and research institutes in different parts of the world.

Professor Srivastava's academic as well as personal life has been greatly enriched by the dedicated and whole-hearted support of his wife, Prof. Dr. Rekha Srivastava, who is also a mathematician and a colleague in the same Department of Mathematics and Statistics at the University of Victoria, and by his two children, Sapna Srivastava (who is currently working as a journalist in the Seattle area in the USA after gaining her Master's degree in Journalism from Fordham University in New York) and Dr. Gautam Mohan Srivastava (who is currently teaching in the Department of Computer Science in the Faculty of Engineering at the University of Victoria). Many of Professor Srivastava's teachers (especially those at the University of Allahabad), too, deserve to be credited for his choice of teaching career and for his academic and scholarly accomplishments in his chosen profession.

When not fully immersed into his research and writing, Professor Srivastava prefers to pursue one of his main hobbies: watching movies and serials (mostly in Hindi) on largescreen television at home with his family. His continuing interest in sports is exemplified by his active participation in hockey games until recently and by his regular attendance at baseball games - live (especially when his son, who is presently also a successful (and nationally well-recognized) baseball coach, used to play) or on television - with his wife (who incidentally got him deeply interested in baseball games, too). Besides, the spiritual and religious inclinations of Professor Srivastava and his wife, which were implanted in them by the cultural and spiritual environment of their respective families, grew much stronger in their own family life. He and his wife, together with their children, have contributed significantly to the community and other related services of the society.

\section{Honors, awards and other accomplishments}

Professor Srivastava has published 21 books, monographs and edited volumes, 30 book (and encyclopedia) chapters, 43 papers in international conference proceedings, and over 1,000 scientific research journal articles on various topics of mathematical analysis and applicable mathematics. In addition, he has written forewords to several books by other authors and to several special issues of scientific journals. He has also edited (and contributed to) many volumes dedicated to the memories of famous mathematical scientists. Citations of his research contributions can be found in many books and monographs, Ph. D. and D. Sc. theses, and scientific journal articles, much too numerous to be recorded here. Currently, he is actively associated editorially (that is, as an editor, honorary editor, senior editor, associate editor, or editorial board member) with over 200 international scientific research journals. His biographical sketches (many of which are illustrated with his photograph) have appeared in various issues of more than 50 international biographies, directories, and Who's Who's. 
Professor Srivastava's over 50-year career as a university-level teacher and as a remarkably prolific researcher in many different areas of the mathematical, physical, and statistical sciences is highlighted (among other things) by the fact that he has collaborated and published joint papers with as many as 385 mathematicians, physicists, statisticians, chemists, astrophysicists, geochemists, and information and business management scientists who are scattered throughout the world, thereby qualifying for his Erdös number 2, implying that at least one of Professor Srivastava's co-authors is a co-author of the famous Hungarian mathematician, Paul Erdös (1913-1996). Professor Srivastava's collaboration distances with other famous scientists include his Einstein number 3, Pólya number 3, von Neumann number 3, Wiles number 3, and so on.

In the leading newspaper, The Globe and Mail (Toronto, March 27, 2012, Page B7 et seq.), Professor Srivastava was listed in the second place among Canada's top researchers in the discipline of Mathematics and Statistics in terms of productivity and impact based upon a measure of citations of their published works.

Some of the most recent prizes and distinctions awarded to Professor Srivastava include (for example) the following items:

1. NSERC 25-Year Award: University of Victoria, Canada (2004)

2. The Nishiwaki Prize: Japan (2004)

3. Doctor of Science (Honoris Causa): Chung Yuan Christian University, Chung-Li, Taiwan, Republic of China (2006)

4. Doctor of Science (Honoris Causa): '1 Decembrie 1918' University of Alba Iulia, Romania (2007)

\section{Research contributions}

Many mathematical entities and objects are attributed to (and named after) him. These entities and objects include (among other items) Srivastava's polynomials and functions, Carlitz-Srivastava polynomials, Srivastava-Buschman polynomials, SrivastavaSinghal polynomials, Chan-Chyan-Srivastava polynomials, Erkuş-Srivastava polynomials, Srivastava-Daoust multivariable hypergeometric function, Srivastava-Panda multivariable $H$-function, Singhal-Srivastava generating function, Srivastava-Agarwal basic (or q-) generating function, and $\mathrm{Wu}$-Srivastava inequality in the field of higher transcendental functions; Srivastava-Owa, Choi-Saigo-Srivastava, Jung-Kim-Srivastava, Liu-Srivastava, Cho-Kwon-Srivastava, Dziok-Srivastava, Srivastava-Attiya and Srivastava-Wright operators in the field of geometric function theory in complex analysis; Srivastava-Gupta operator in the field of approximation theory; the Srivastava, Adamchik-Srivastava and Choi-Srivastava methods in the field of analytic number theory; and so on.

Professor Srivastava has supervised (and is currently supervising) a number of postgraduate students working toward their Master's, Ph. D. and/or D. Sc. degrees in different parts of the world. Besides, many post-doctoral fellows and research associates have worked with him at West Virginia University in the USA and at the University of Victoria in Canada.

Some of the significant and remarkable contributions by Professor Srivastava are listed below under each of the main topics of his current research interests.

(i) Real and complex analysis: A unified theory of numerous potentially useful function classes, and of various integral and convolution operators using hypergeometric functions, especially in geometric function theory in complex analysis, and several classes of analytic and geometric inequalities in the field of real analysis. 
(ii) Fractional calculus and its applications: Generalizations of such classical fractionalcalculus operators as the Riemann-Liouville and Weyl operators together with their fruitful applications to numerous families of differential, integral, and integro-differential equations, especially some general classes of fractional kinetic equations, and also to some Volterra-type integro-differential equations which emerge from the unsaturated behavior of the free electron laser.

(iii) Integral equations and transforms: Explicit solutions of several general families of dual series and integral equations occurring in potential theory; unified theory of many known generalizations of the classical Laplace transform (such as the Meijer and Varma transforms) and of other multiple integral transforms by means of the Whittaker $W_{\kappa, \mu}$ function and the (Srivastava-Panda) multivariable $H$-function in their kernels.

(iv) Higher transcendental functions and their applications: Discovery, introduction, and systematic (and unified) investigation of a set of 205 triple Gaussian hypergeometric series, especially the triple hypergeometric functions $H_{A}, H_{B}$, and $H_{C}$, added to the 14member set conjectured and defined in 1893 by Giuseppe Lauricella (1867-1913). Unified theory and applications of the multivariable extensions of the celebrated higher transcendental ( $\Psi$ - and $H-$ ) functions of Charles Fox (1897-1977) and Edward Maitland Wright (1906-2005), and also of the Mittag-Leffler $E$-functions named after Gustav Mittag-Leffler (1846-1927). Mention should be made also of his applications of some of these higher transcendental functions in quantum and fluid mechanics, astrophysics, probability distribution theory, queuing theory and other related stochastic processes, and so on.

(v) $q$-Series and $q$-polynomials: Basic theory of general $q$-polynomial expansions for functions of several complex variables, extensions of several celebrated $q$-identities of Srinivasa Ramanujan (1887-1920), and systematic introduction and investigation of multivariable basic (or $q$-) hypergeometric series.

(vi) Analytic number theory: Presentation of several computationally-friendly and rapidly-converging series representations for Riemann's zeta function, Dirichlet's $L$-series, introduction and application of some novel techniques for closed-form evaluations of series involving a wide variety of sequences and functions of analytic number theory, and so on. His applications of (especially) the Hurwitz-Lerch zeta function in geometric function theory in complex analysis and in probability distribution theory and related topics of statistical sciences deserve to be recorded here.

Professor Srivastava's publications have been reviewed by (among others) Mathematical Reviews (USA), Referativnyi Zhurnal Matematika (Russia), Zentralblatt für Mathematik (Germany), and Applied Mechanics Reviews (USA) under various 2010 Mathematical Subject Classifications (MathSciNet) including (for example) the following general classifications:

01 History and Biography

05 Combinatorics

11 Number Theory

15 Linear and Multilinear Algebra; Matrix Theory

26 Real Functions

30 Functions of a Complex Variable

31 Potential Theory

33 Special Functions

34 Ordinary Differential Equations 
35 Partial Differential Equations

39 Difference and Functional Equations

40 Sequences, Series, Summability

41 Approximations and Expansions

42 Fourier Analysis

44 Integral Transforms, Operational Calculus

45 Integral Equations

46 Functional Analysis

47 Operator Theory

58 General Global Analysis, Analysis on Manifolds

60 Probability Theory and Stochastic Processes

62 Statistics

76 Fluid Mechanics

78 Optics, Electromagnetic Theory

81 Quantum Theory

85 Astronomy and Astrophysics

90 Operations Research, Mathematical Programming

91 Game Theory, Economics, Social and Behavioral Sciences

93 Systems Theory, Control

\section{Submit your manuscript to a SpringerOpen ${ }^{\circ}$} journal and benefit from:

- Convenient online submission

Rigorous peer review

- Immediate publication on acceptance

- Open access: articles freely available online

- High visibility within the field

- Retaining the copyright to your article 